\title{
Peritonitis and catheter exit-site infection in patients on peritoneal dialysis at home ${ }^{1}$
}

\author{
Ana Cristina Freire Abud ${ }^{2}$ \\ Luciana Kusumota ${ }^{3}$ \\ Manoel Antônio dos Santos ${ }^{4}$ \\ Flávia Fernanda Luchetti Rodrigues ${ }^{5}$ \\ Marta Maria Coelho Damasceno ${ }^{6}$ \\ Maria Lúcia Zanetti ${ }^{3}$
}

Objective: to analyze the complications related to peritonitis and catheter exit-site infections, in patients on peritoneal dialysis at home. Method: quantitative and cross-sectional study, carried out with 90 patients on peritoneal dialysis at home, in a municipality in the Northeast region of Brazil. For data collection, it was used two structured scripts and consultation on medical records. Descriptive analysis and comparison tests among independent groups were used, considering $p<0.05$ as level of statistical significance. Results: by comparing the frequency of peritonitis and the length of treatment, it was found that patients over two years of peritoneal dialysis were more likely to develop peritonitis $\left(X^{2}=6.39 ; p=0.01\right)$. The number of episodes of peritoneal catheter exit-site infection showed association with the length of treatment $(U=224,000$; $\mathrm{p}=0.015)$. Conclusion: peritonitis and catheter exit-site infection are associated with the length of treatment.

Descriptors: Peritoneal Dialysis; Home Nursing; Nursing Care; Education, Nursing; Infection; Peritonitis.

\footnotetext{
Paper extracted from doctoral dissertation "Attention in Peritoneal Dialysis at Home", presented to Escola de Enfermagem de Ribeirão Preto, Universidade de São Paulo, PAHO/WHO Collaborating Centre for Nursing Research Development, Ribeirão Preto, SP, Brazil.

2 PhD, Adjunct Professor, Centro de Ciências Biológicas e da Saúde, Universidade Federal de Sergipe, Aracaju, SE, Brazil.

3 PhD, Associate Professor, Escola de Enfermagem de Ribeirão Preto, Universidade de São Paulo, PAHO/WHO Collaborating Centre for Nursing Research Development, Ribeirão Preto, SP, Brazil.

${ }^{4}$ PhD, Associate Professor, Faculdade de Filosofia, Ciências e Letras de Ribeirão Preto, Universidade de São Paulo, Ribeirão Preto, SP, Brazil.

5 Doctoral student, Escola de Enfermagem de Ribeirão Preto, Universidade de São Paulo, PAHO/WHO Collaborating Centre for Nursing Research Development, Ribeirão Preto, SP, Brazil.

${ }^{6}$ PhD, Adjunct Professor, Faculdade de Farmácia, Odontologia e Enfermagem, Universidade Federal do Ceará, Fortaleza, CE, Brazil.
}

Corresponding Author: Maria Lúcia Zanetti

Universidade de São Paulo. Escola de Enfermagem de Ribeirão Preto Departamento de Enfermagem Geral e Especializada

Av. Bandeirantes, 3900

Bairro: Monte Alegre

CEP: 14040-902, Ribeirão Preto, SP, Brasi

E-mail: zanetti@eerp.usp.br
Copyright () 2015 Revista Latino-Americana de Enfermagem This is an Open Access article distributed under the terms of the Creative Commons Attribution Non-Commercial License (CC BY-NC).

This license lets others distribute, remix, tweak, and build upon your work non-commercially, and although their new works must also acknowledge you and be non-commercial, they don't have to license their derivative works on the same terms. 


\section{Introduction}

The prevalence of dialysis patients in Brazil shows upward trends. The country is the third in the world in number of patients on dialysis, and only $9.4 \%$ are in Peritoneal Dialysis (PD) ${ }^{(1-2)}$. The Brazilian Unified Health System (SUS) finances approximately $80 \%$ of the PD procedures and shows expressive evidence of saturation regarding the demand for individuals with terminal Chronic Kidney Disease (CKD) ${ }^{(2-3)}$. CKD in its end stage has as treatment, the Renal Replacement Therapy (RRT), which is represented by hemodialysis, peritoneal dialysis and kidney transplantation ${ }^{(3-4)}$.

Particularly, in the case of Peritoneal Dialysis (PD), there are the Continuous Ambulatory Peritoneal Dialysis (CAPD) and the Automated Peritoneal Dialysis (APD) as treatment modalities. These modalities can be performed at the patients' homes(3).

Therefore, the nursing team must teach and supervise the patient and/or caregiver about home conditions, equipment, supplies and procedures, for carrying out the PD. An accurate diagnosis of the living conditions, cognitive and motor skills of the patient and its family is crucial in preventing complications ${ }^{(5-6)}$.

Among the infectious complications, it is highlighted the Catheter Exit-Site Infection (CESI) and peritonitis. The CESI is an infectious complication, characterized by the presence of purulent secretion, with or without erythema of the pericatheter skin. Swelling, erythema and crust or granuloma may also be present. Positive results obtained in the culture of the material collected from secretions contributes to diagnosis and treatment. Peritonitis is considered a serious complication related to the dialysis method and presents high morbidity and mortality rates in patients with $\mathrm{CKD}^{(7-9)}$.

In a review of national and international literature on CESI and peritonitis, it was found that peritonitis is the main complication related to PD. Thus, the performance of the professional team can contribute to improving the quality of PD, strengthening the prevention strategies of peritonitis episodes. In this fashion, researchers deepened the studies, searching for evidence regarding the inflammatory, clinical and socioeconomic markers, as predictors of clinical outcomes, in order to strengthen the strategies for reducing the inflammatory burden, and, most of these studies was carried out in hospital environments and nephrology clinics $^{(5-9)}$. However, there are no studies in the national context about the difficulties of patients on PD performed at home, which can lead to complications related to peritonitis and CESI.
In considering the paucity of research explaining the implications of this complex treatment for the appearance of complications, this study aimed to analyze the complications related to peritonitis and CESI, in patients on PD performed at home. It is expected that this research can provide information for the planning and continuing education of patients on PD performed at home.

\section{Method}

This is a quantitative, cross-sectional and retrospective study, performed in a nephrology clinic of the municipality of Aracaju, in the state of Sergipe (SE), Brazil, from January to July 2012. The study population consisted of 416 patients on renal replacement therapy. Of these, 305 were on hemodialysis and 111 on PD and, of these, 55 were on Automated Peritoneal Dialysis (APD) and 56 on Continuous Ambulatory Peritoneal Dialysis (CAPD).

The inclusion criteria were: patients on APD and CAPD, with experience of at least six months in PD, aged 18 years or over, residing in the state of Sergipe and having medical records of PD treatment, available in the electronic system, Dialsist ${ }^{\circledR}$ version 2.0. This period was proposed taking into account the need for experience in relation to PD performed at home. Of the 111 patients on peritoneal dialysis, five were aged below 18 years, four lived outside the state of Sergipe, one was on intermittent PD and 11 were on PD for less than six months. The eligible participants were 90 patients who met the inclusion criteria, corresponding to approximately $85 \%$ of patients on PD of the dialysis clinic, in January 2012.

It was selected the sociodemographic (age, gender, education and family income) and clinical variables (length of treatment, primary disease and nonattendance at medical appointments) and the variables related to the occurrence of infectious complications (peritonitis and CESI). It was considered with low education level the patients with up to four complete years of study, average education from five to 11 years of study, and high education level, 12 years of study or over. Peritonitis was considered when the patient presented cloudy dialysate fluid, with leukocytes counts above 100/ $\mathrm{mm}^{3}$ and polymorphonuclear $>50 \%$ or positive results in the microbiological examination of the dialysate. The presence of CESI was identified by the occurrence of purulent discharge, with or without erythema, on the skin of the epidermis-catheter interface ${ }^{(10)}$. It was 
also used the results of microbiological examination of the material collected at the catheter exit-site, with inflammatory signs. The information about peritonitis and CESI were collected as they were registered in the medical records.

Data collection took place in three stages: the first was related to the selection of the medical records, according to predefined inclusion criteria. From them, it was carried out a search on the patients' addresses and their telephone contacts. Following, it was established telephone contact with patients and/ or caregivers, requesting their authorization for home visits and informing the purpose of the research. This contact occurred approximately 24 hours before home visits. This short period, estimated from the scheduling of the meeting until its completion, was important to ensure that there would not be changes in the research scenario.

In the second stage, it was carried out home visits. In this stage, two researchers, properly trained for data collection, performed clarifications on the nature and objectives of the research, obtaining the written signature of the patients on the Informed Consent Form. Following, it was carried out an interview using two structured scripts: one to obtain the sociodemographic and clinical data and the other for the variables related to infectious complications related to PD performed at home. In the third and final stage, it was carried out a search in the medical records of the patient, in order to complement the data on infectious complications. The Committee of Ethics and Research involving Humans approved the project, under Protocol number CAAE 0310.0.107.000-11.

Data collection were entered and tabulated using Excel 2007 software. In order to facilitate analysis, it was adopted statistical treatment, using the Statistical Package for the Social Sciences (SPSS) software, version 20 and the Epi info software, version 3.5.1, of the Centers for Disease Control and Prevention (CDC). Descriptive statistics was used for univariate frequency analysis, in the characterization of participants and nonparametric tests, such as the Mann-Whitney $U$ test, for the numerical variables. For analysis of the categorical variables, it was adopted the Chi-square test. The null hypothesis was rejected with significance level of $5 \%$ ( $p$ $<0.05)^{(11)}$.

\section{Results}

Of the $90(100 \%)$ patients on PD performed at home, $37(41.1 \%)$ were in the $60-79$ age group. As to gender, there was a predominance of males, 51 (56.6\%). Regarding the education, 28 (31.1\%) had five to eight years of study. Regarding the per capita income, the majority, 58 (64.4\%) received less than one minimum wage. Regarding the primary disease, it was found that most, 49 (54.4\%), was admitted to the program of PD performed at home with diagnosis of nonspecific kidney disease, followed by 17 (18.8\%) with a glomerular disorder in diabetes mellitus and 10 $(11.1 \%)$ with hypertensive renal disease.

As for the occurrence of peritonitis, it was found that $52(57.8 \%)$ patients showed no occurrence of peritonitis, $24(26.7 \%)$ had an episode and $14(15.5 \%)$ had two or more episodes, from the admission of the patient on PD to data collection performed at home, which was carried out from January to July 2012.

By comparing the frequency of peritonitis and the length of treatment, it was found that patients on DP for more than two years, were more likely to have peritonitis $\left(X^{2}=6.39 ; p=0.01\right)$, thus showing statistically significant difference. The average length of treatment was 35 months and the median was 23 months. Among the patients studied, six presented three or more episodes of peritonitis, of which one presented six episodes of peritonitis (Table 1 ).

Table 1 - Numerical distribution of occurrence of peritonitis, according to the length of treatment. Aracaju, SE, Brazil, 2012

\begin{tabular}{|c|c|c|c|c|c|c|c|c|c|c|}
\hline \multirow{3}{*}{$\begin{array}{l}\text { Length of treatment } \\
\text { in months }\end{array}$} & \multicolumn{10}{|c|}{ Episodes of peritonitis } \\
\hline & \multicolumn{2}{|c|}{0} & \multicolumn{2}{|c|}{1} & \multicolumn{2}{|c|}{2} & \multicolumn{2}{|c|}{$\geq 3$} & \multicolumn{2}{|c|}{ Total } \\
\hline & $\mathrm{n}$ & $\%$ & $\mathrm{n}$ & $\%$ & $\mathrm{n}$ & $\%$ & $\mathbf{n}$ & $\%$ & $\mathrm{n}$ & $\%$ \\
\hline Up to 12 & 19 & 70.4 & 7 & 25.9 & 1 & 3.7 & - & - & 27 & 100.0 \\
\hline 13 to 24 & 14 & 73.7 & 3 & 15.8 & 2 & 10.5 & & & 19 & 100.0 \\
\hline 25 to $36^{*}$ & 4 & 40.0 & 3 & 30.0 & 1 & 10.0 & 2 & 20.0 & 10 & 100.0 \\
\hline$>36^{*}$ & 15 & 44.1 & 11 & 32.3 & 4 & 11.8 & 4 & 11.8 & 34 & 100.0 \\
\hline Total & 52 & 57.8 & 24 & 26.7 & 08 & 8.9 & 6 & 6.6 & 90 & 100.0 \\
\hline
\end{tabular}

* For exposure $>24$ months $\mathrm{p}=0.01 ; \mathrm{X}^{2}=6.39$ 
Of the $58(64.5 \%)$ patients who had per capita family income lower than one minimum wage, 17 (18.9\%) had an episode, and nine (10.0\%) had two or more episodes of peritonitis. From the association between episodes of peritonitis and income, it was observed that the higher the per capita income, the lower were the episodes of peritonitis presented.

Patients with low education level represented $40 \%$ of patients. However, there were no statistically significant differences between the occurrence of peritonitis and level of education of the patient, with the values for the patient's education level $\left(x^{2}=0.55 ; p=0.45\right)$ and for the caregiver's education level $\left(x^{2}=0.06 ; p=0.8\right)$. Eleven patients did not have caregivers.
It was found a statistically significant association between the occurrence of peritonitis and the number of non-attendance at medical appointments $\left(x^{2}=6.28\right.$; $\mathrm{p}=0.01$ ). For association purposes, it was considered as risk the patients who have had four or more nonattendance at medical appointments, from the date of admission on peritoneal dialysis. It was found that the number of non-attendance in relation to the length of treatment was low in the first year and the longer the length of treatment, the greater the number of non-attendance. In this clientele, 14 (15.5\%) had an episode of peritonitis and seven (7.8\%) had two or more episodes (Table 2).

Table 2 - Numerical distribution of occurrence of peritonitis and total number of non-attendance at medical appointments. Aracaju, SE, Brazil, 2012

\begin{tabular}{|c|c|c|c|c|c|}
\hline \multirow{3}{*}{$\begin{array}{c}\text { Number of } \\
\text { non-attendance }\end{array}$} & \multicolumn{5}{|c|}{ Episodes of peritonitis } \\
\hline & 0 & 1 & 2 & $\geq 3$ & Total \\
\hline & n (\%) & n (\%) & n (\%) & n (\%) & n (\%) \\
\hline Zero & $13(14.4)$ & $3(3.3)$ & $1(1.1)$ & $1(1.1)$ & $18(20.0)$ \\
\hline One & $11(12.2)$ & $3(3.3)$ & $1(1.1)$ & - & $15(16.7)$ \\
\hline Two & $9(10.0)$ & $3(3.3)$ & $1(1.1)$ & $1(1.1)$ & $14(15.5)$ \\
\hline Three & $5(5.6)$ & $1(1.1)$ & $1(1.1)$ & $1(1.1)$ & $8(8.9)$ \\
\hline Four & $1(1.1)$ & $1(1.1)$ & $1(1.1)$ & $2(2.2)$ & $5(5.5)$ \\
\hline Five or more & $13(14.4)$ & $13(14.4)$ & $3(3.3)$ & $1(1.1)$ & $30(33.3)$ \\
\hline Total & $52(57.8)$ & $24(26.7)$ & $8(8.9)$ & $6(6.7)$ & $90(100)$ \\
\hline
\end{tabular}

$* X^{2}=6.28$;

$\mathrm{p}=0.01$

Regarding the occurrence of CESI, 56 (62.2\%), patients had one or more episodes. By comparing the CESI and the length of treatment, it was observed a higher number of patients affected by the infection in the first year, when compared to the second and third years. After the third year, the number of affected patients increased again (Table 3 ).

Table 3 - Numerical distribution of occurrence of catheter exit-site infection (CESI), according to the length of treatment. Aracaju, SE, Brazil, 2012

\begin{tabular}{|c|c|c|c|c|c|c|c|c|c|c|c|c|}
\hline \multirow{3}{*}{$\begin{array}{l}\text { Length of treatment } \\
\text { in months }\end{array}$} & \multicolumn{12}{|c|}{ Catheter Exit-Site Infection } \\
\hline & \multicolumn{2}{|c|}{0} & \multicolumn{2}{|c|}{1} & \multicolumn{2}{|c|}{2} & \multicolumn{2}{|c|}{3} & \multicolumn{2}{|c|}{$\geq 4$} & \multicolumn{2}{|c|}{ Total } \\
\hline & $\mathbf{n}$ & $\%$ & $\mathbf{n}$ & $\%$ & $\mathbf{n}$ & $\%$ & $\mathbf{n}$ & $\%$ & $\mathbf{n}$ & $\%$ & $\mathbf{n}$ & $\%$ \\
\hline Up to 12 & 14 & 51.8 & 7 & 25.9 & 4 & 14.8 & 1 & 3.7 & 1 & 3.7 & 27 & 100.0 \\
\hline 13 to 24 & 10 & 52.6 & 6 & 31.5 & 3 & 15.7 & - & - & - & - & 19 & 100.0 \\
\hline 25 to 36 & 3 & 30.0 & 3 & 30.0 & 1 & 10.0 & 1 & 10.0 & 2 & 20.0 & 10 & 100.0 \\
\hline$>36$ & 7 & 20.5 & 5 & 14.7 & 6 & 17.6 & 3 & 8.8 & 13 & 38.2 & 34 & 100.0 \\
\hline Total & 34 & 37.7 & 21 & 23.3 & 14 & 15.5 & 05 & 5.5 & 16 & 17.7 & 90 & 100.0 \\
\hline
\end{tabular}

The association between the number of episodes of CESI and the length of treatment, by using the Mann-Whitney $U$ test, showed statistical significance $(U=224,000 ; p=0.015)$. Accordingly, patients with two or more episodes of CESI were under treatment for longer $(M=46.22, S D=26.15)$ than those who had only one episode $(M=29.47, S D=28.95)$ (Table 4). 
Table 4 - Numerical distribution of occurrence of catheter exit-site infection (CESI) and length of treatment by means of the Mann-Whitney U test. Aracaju, SE, Brazil, 2012

\begin{tabular}{lccc}
\hline \multicolumn{1}{c}{ Occurrence of Catheter Exit-Site Infection } & $\mathbf{n}$ & $\begin{array}{c}\text { Length of treatment in months } \\
\text { (average) }\end{array}$ & Standard Deviation \\
\hline No Catheter Exit-Site Infection & 34 & 27.41 & 28.97 \\
An episode & 21 & 29.47 & 28.95 \\
Two or more episodes & 35 & $46.22^{*}$ & 26.15 \\
Total & 90 & & \\
\hline
\end{tabular}

$* \mathrm{U}=224,000$;

$\mathrm{p}=0.015$

No statistically significant association was verified when the occurrence of CESI was compared with the patients' education level. It was observed that, 20 $(22.2 \%)$ patients with low education level had one or more episodes of CESI and 36 (40.0\%) had medium and high education levels.

Regarding the occurrence of CESI and the total number of non-attendance at medical appointments, it was observed that nine patients, although they had not displayed non-attendance, they had one or more
CESI episodes, and 21 of them with five or more nonattendance had one or more episodes, with no statistically significant difference $(U=314,000 ; p=0.362)$.

Regarding the occurrence of CESI and the family income, it was observed that most of the affected patients received less than one minimum wage. Of these, it is highlighted that 14 patients who presented an episode, whereas 22 patients presented more than two episodes, with statistically significant differences $(\mathrm{CI}=0.246 ; \mathrm{p}<0.019)$ (Table 5).

Table 5 - Numerical and percentage distribution of episodes of catheter exit-site infection (CESI), according to per capita family income in minimum wages. Aracaju, SE, Brazil, 2012

\begin{tabular}{lccccc}
\hline & \multicolumn{5}{c}{ Catheter Exit-Site Infection } \\
\cline { 2 - 6 } & $\mathbf{0}$ & $\mathbf{1}$ & $\mathbf{2}$ & $\mathbf{2}$ & $\mathbf{n}(\%)$ \\
\cline { 2 - 5 } & $\mathbf{n}(\%)$ & $\mathbf{n}(\%)$ & $11(12.2)$ & $11(12.2)$ & $58(64.5)$ \\
\hline$\leq 1$ & $22(24.4)$ & $14(15.6)^{\dagger}$ & $3(3.3)$ & $3(3.3)$ & $18(20.0)$ \\
$\leq 2$ & $8(8.9)$ & $4(4.4)$ & - & $5(5.6)$ & $9(10.0)$ \\
$<3$ & $3(3.3)$ & $1(1.1)$ & - & $2(2.2)$ & $5(5.5)$ \\
3 or + & $1(1.1)$ & $2(2.2)$ & $14(15.6)$ & $21(23.3)$ & $90(100)$ \\
Total & $34(37.8)$ & $21(23.3)$ & & & $\mathbf{n}$ \\
\hline
\end{tabular}

*Minimum Wage (MW) in 2013, in Brazil (R\$622/month)

$+\mathrm{IC}=0.246 ; \mathrm{p}<0.019$

In the face of the occurrence of infectious complications, $10(11.1 \%)$ patients were submitted to catheter exchange. The reasons registered for catheter exchange were: seven for peritonitis, two for tunelitis and one for CESI.

Regarding the conditions of the catheter exit-site on the skin, observed during home visits, 67 (74.5\%) patients presented intact skin around peritoneal catheter, three (3.3\%) presented heat, redness and pain, which were evaluated as inflammation grade 1 , in 16 (17.8\%) patients, grade 3, due to the presence of crust, and four $(4.4 \%)$ with purulent exudate, as grade 4 . As for the fixing of the catheter to the skin, 68 (75.5\%) patients were prescribed with the catheter fixed to the skin and $22(24.5 \%)$ with it loose.

\section{Discussion}

By analyzing the results obtained in relation to sociodemographic variables, it was observed consistency with those found by the Brazilian Society of Nephrology ${ }^{(2)}$ and by a cohort study named BRAZPD, performed in the South and Southeast regions of Brazil(12).

The complexity of the peritoneal dialysis procedure is recognized. In this sense, the sociodemographic variables must be considered in establishing the diagnosis of cognitive, motor and affective skills of the patients and/or caregivers by the nurses, in order to prevent infectious complications in $\mathrm{PD}^{(13)}$.

The results obtained in this study showed that, $54.5 \%$ of patients were admitted to the dialysis program 
with a primary diagnosis of unspecific kidney disease. This result shows that, at the study site, the number of patients on renal replacement therapy without knowledge of the primary disease is high. This may reflect the time spent by the patient waiting for the first medical consultation.

Regarding the length of treatment, it was observed that majority of the patients was found between 13 and 36 months on dialysis (32.2\%), followed by six to 12 months $(30.0 \%)$. The high rate of mortality and the presence of complications have been reported as reasons for abandonment of the peritoneal dialysis program by patients.

It is recognized that investments have been made for the implementation of peritoneal dialysis programs in Brazil. However, by analyzing the causes of abandonment of the program by patients, it was observed that the main reason is the death. By analyzing this data, on life expectancy, it was observed that, according to the Brazilian Institute of Geography and Statistics, the Northeast region has the lowest life expectancy in the country. Moreover, it is the region with the third highest death rate related to dialysis technique and with only $34.89 \%$ of patients who had pre-dialysis follow-up, compared to other regions of the country ${ }^{(12)}$.

The lack of follow-up in the pre-dialysis period, the difficulty of detection of primary renal disease and the low socioeconomic status of the population are some factors contributing to the failure of dialysis.

Regarding the occurrence of peritonitis, nearly half of patients $(42.2 \%)$ had peritonitis record in their medical charts, and $15.5 \%$ of them had two or more episodes. Peritonitis is a major complication of peritoneal dialysis, either in manual mode (CAPD) or automated mode (APD) $)^{(14)}$.

The mortality rate from infection caused by peritoneal dialysis is approximately $18 \%$, due to peritonitis. However, only $4 \%$ of episodes of peritonitis have death as outcome. Severe and prolonged damage to peritoneal membrane, which leads to failure of the peritoneum, causes peritonitis be considered as the main cause of exchange of peritoneal dialysis for hemodialysis by patients ${ }^{(10)}$.

By analyzing the frequency of peritonitis with respect to length of treatment, it was observed a statistically significant association, differing from a study performed in the West region of the state of Paraná, in which no statistical evidence was found ${ }^{(14)}$.

Patients with two or more years of treatment were more likely to develop peritonitis. Regarding the increase of peritonitis cases in the first year, these data were also observed in two studies performed in two dialysis centers in the South region of Brazil(15). The probabilities of patients undergoing peritoneal dialysis to develop peritonitis in the sixth month and at the end of the first year after peritoneal catheter implant are $53.6 \%$ and $57.8 \%$, respectively ${ }^{(16-17)}$.

By analyzing the occurrence of peritonitis and the number of non-attendance at medical appointments, it was found statistical significance. Patients who have had four or more non-attendance at medical appointments are 1.94 times more likely to have peritonitis. The constant non-attendance at medical appointments leads to discontinuation of treatment and may reflect the patient's difficulty regarding the requirements of the therapeutic approach. The importance of attendance of patients in the scheduled medical follow-up appointments should be included in the theoretical teaching content. Some factors are pointed out for the success of therapy, such as the commitment of caregivers, adherence to guidelines and involvement of the patient and/or caregiver with the proposed treatment ${ }^{(8)}$.

By analyzing the presence of CESI, it was observed a higher number of affected patients in the first year, compared to the second and third years in PD. By comparing the presence of catheter exit-site infection and the length of treatment, statistical significance was verified. CESI and infection of the subcutaneous tunnel are considered serious accidents in PD and are related to high morbidity due to these infections, which are difficult to treat, causing the removal of the peritoneal catheter ${ }^{(18)}$

By analyzing the occurrence of CESI and the number of non-attendance at medical appointments, it was not observed statistical significance. Catheter exit-site infections are predominantly caused by Staphylococcus aureus or gram-negative organisms. A study indicated that the main risk factor for the occurrence of catheter exit-site infection is being a nasal staphylococcus carrier(19). Thereby, it is reinforced the importance of hand hygiene and use of masks by patients and caregivers, while performing peritoneal dialysis procedure.

By analyzing CESI and family income, it was found a statistical significance. It was observed that the number of CESI occurrences was higher in those patients with per capita income lower than one minimum wage. It is recognized that, a significant portion of poor health is a result of poverty and low education levels or its consequences combined with 
a poor diet or lack of basic sanitation, among other specific factors.

In spite of the technological resources available in controlling infections, regarding the hand hygiene, it is believed that correct technique can prevent infection, since the hands can become a vehicle of transmission of microorganisms ${ }^{(20)}$. Thereby, permanent supervision by the nurse of the dialysis unit on the correct hand hygiene, performed by both the health team and the patients and caregivers, can minimize the appearance of infection. At home, in addition to teaching this skill to patients and caregivers, periodic supervision is also required.

It is recognized that, in the face of the occurrence of infectious and mechanical complications, there may be the need for exchange of the peritoneal catheter. Peritonitis was the cause registered in the medical records for the largest number of substitutions, followed by inadequate drainage of dialysis liquid.

Regarding the conditions of the catheter exitsite, it was observed that most patients showed intact pericatheter skin. According to the recommendations of the International Society for Peritoneal Dialysis (ISPD) (2010), catheter exit-site infection is defined by the presence of purulent drainage, with or without erythema in the skin-catheter interface ${ }^{(10)}$. Based on this concept, $14.4 \%$ of patients with purulent drainage in the catheter exit-site were identified during home visits, therefore, classified as patients with catheter exit-site infection.

As regards the fixing of the catheter to the skin, $75.5 \%$ of patients had catheters without fixing in the abdomen. This finding corroborates with the definition of the recommendations of the ISPD (2010), which states that presence of erythema without purulent drainage can occur as a simple skin pericatheter trauma(10).

The care for the dialysis catheter, after implantation in the abdomen, includes its immobilization in the abdominal region, showering only when the patient has a safe healing and avoiding bathing and swimming because of the risk of infection related to the presence of bacteria in the water(21-22).

The maintenance of peritoneal catheter is the patient's responsibility, with the supervision of the healthcare team. The nurses play a key role, since they are responsible for the professional training of patients, families and caregivers. The constant monitoring favors safety for the procedure in $\mathrm{PD}^{(23)}$, in order to reduce future complications and maintain the quality of life of patients.

\section{Conclusions}

Patients with two or more years of treatment were more likely to have peritonitis. There was association between the occurrence of peritonitis and the number of non-attendance at medical appointments. By comparing CESI and length of treatment, it was observed a higher number of patients affected in the first year, compared to the second and third years. There was association between CESI and length of treatment.

This study highlights the need for permanent evaluation by nurses on PD procedure performed by patients, family members or caregivers, since during treatment the patient may be vulnerable and neglect the care, such as proper hand hygiene and hygiene of the skin near the insertion of the catheter, among other actions.

\section{References}

1. KDIGO. Clinical Practice Guidline for the Evaluation and Management of Chronic Kidney Disease. Other complications of CKD: CVD, medication dosage, patient safety, infections, hospitalizations, and caveats for investigating complications of CKD. Kidney Int. 2012;3:91-111.

2. Sesso RC, Lopes AA, Thomé FS, Lugon JR, Watanabe Y, Santos DR. Diálise Crônica no Brasil - Relatório do Censo Brasileiro de Diálise, 2011. J Bras Nefrol. 2012;34(3):272-7.

3. Pecoits-Filho RI, Abensur $H$, Cueto-Manzano $A M$, Dominguez J, Divino JC Filho, Fernandez-Cean J, et al. Overview of peritoneal dialysis in Latin America. Perit Dial Int. 2007;27(3):316-21.

4. Riella MC. Historical point of view: hitory of CAPD in Brazil. J Bras Nefrol. 1994;16(3):117-8.

5. Abrahão SS, Ricas J, Andrade DF, Pompeu FC, Chamahum L, Araújo TM. Study about the Practice of Peritoneal Dialysis. J Bras Nefrol. 2010;32(1):45-50.

6. Torreão $\mathrm{CL}$, Souza $\mathrm{SR}$, Aguiar BGC. Cuidados de enfermagem ao cliente em diálise peritoneal: contribuição para prática e manejo clínico. Rev Pesq Cuid Fundamental. 2009;1(2):317-25.

7. Lobo JVD, Villar KR, Andrade MP, Bastos KA. Preditores de peritonite em pacientes em um programa de diálise peritoneal. J Bras Nefrol. 2010;32(2):156-64.

8. Abrahão SS, Ricas J, Andrade DF, Pompeu FC, Chamahum L, Araújo TM, et al. Risk factors for peritonitis and hospitalizations. J Bras Nefrol. 2010;32(1):100-6. 
9. Yeoungjee C, Carmel MH, David WJ. Clinical Causes of Inflammation in Peritoneal Dialysis Patients. Int J Nephrol. 2014;2014:1-9.

10. Li PK, Szeto CC, Piraino B, Bernardini J, Figueiredo $A E$, Gupta A, et al. Peritoneal dialysis-related infections recommendations: 2010 UPDATE. Perit Dial Int. 2011;31(5):512.

11. Vieira S. Bioestatística tópicos avançados. 3 ed. Rio de Janeiro: Elsevier; 2010.

12. Fernandes NMS, Chaoubah A, Bastos K, Lopes AA, Divino-Filho JC, Pecoits-Filho R, et al. Geography of peritoneal dialysis in Brazil: analysis of a cohort of 5,819 patients (BRAZPD). J Bras Nefrol. 2010;32(3):265-71.

13. Bernardini J, Price V, Figueiredo A. Peritoneal dialysis patient training. Perit Dial Int. 2006;26(6):625-32.

14. Peres LBA, Matsuo T, Ann HK, Camargo MTA, Rohde NRS, Uscocovich VSM, et al. Peritonites em diálise peritoneal ambulatorial contínua. Rev Bras Clin Med. 2011;9(5):350-3.

15. Jacobowski JAD, Borella R, Lautert T. Pacientes com Insuficiência Renal Crônica: Causas de saída do Programa de Diálise Peritoneal. Rev Gaúcha Enferm. 2005;26(3):381-91.

16. Pecoits RF, Moraes TP. Diálise Peritoneal. In: Riella MC. Princípios de Nefrologia e Distúrbios Hidroeletrolíticos. 5. ed. Rio de Janeiro: Guanabara Koogan; 2010. p. 1032-46.

17. Bevilacqua JL, Canziani MEF. Monitorização dos parâmetros hematimétricos. J Bras Nefrol. 2007;29(4):7-8.

18. Alves FR. Revisão/Atualização em Diálise: Infecções relacionadas ao cateter. J Bras Nefrol. 1997;19(4):442-6. 19. Leehey DJ, Szeto C, Li PK. Peritonite e Infecção do Local de Saída. In: Daugirdas JT, Blake PG, Ing TS. Manual de Diálise. 4. ed. Rio de Janeiro: Medsi; 2008. p. 383-404.

20. Sadala MLA, Bruzos GAS, Pereira ER, Bucuvic EM. Patients' experiences of peritoneal dialysis at home: a phenomenological approach. Rev. Latino-Am. Enfermagem. 2012;20(1):68-75.

21. Oller GASAO, Ribeiro RCHM, Travagim DSA, Batista MA, Marques S, Kusumota L. Functional independence in patients with chronic kidney disease being treated with haemodialysis1. Rev. Latino-Am. Enfermagem. 2012;20(6):1033-40.

22. Trajano JS, Marques IR. Assistência de enfermagem na diálise peritoneal ambulatorial e hospitalar. Rev Enferm UNISA. 2005;6:53-7.
23. Figueiredo $A F$, Poli-de-Figueiredo $C E$, Meneghetti $F$, Lise GAP, Detofoli CC, Silva LB. Peritonites em pacientes em diálise peritoneal: análise de um centro brasileiro segundo as recomendações da Sociedade Internacional de Diálise Peritoneal. J Bras Nefrol. 2013;35(3):214-9. 